\section{Combined Effects of Ventilation and Irrigation on Temperature, Humidity, Tomato Yield, and Quality in the Greenhouse}

\author{
Jiankun Ge, Linfeng Zhao, and Xuewen Gong \\ North China University of Water Resources and Electric Power, Zhengzhou, \\ 450046, China
}

\author{
Zhiqiang Lai \\ Yellow River Institute of Hydraulic Research, Yellow River Conservancy \\ Commission, Zhengzhou 450003, China
}

\section{Seydou Traore}

Department of Biological and Agricultural Engineering, Texas A\&M University, Scoates Hall, Room\#322, College Station, TX 77843; Global Development \& Innovative Services, FL 33774

\section{Yanbin Li \\ North China University of Water Resources and Electric Power, Zhengzhou, 450046, China}

Hui Long

Water Resources and Hydropower Survey and Design Institute, Baoding, 071000, China

\section{Lei Zhang}

North China University of Water Resources and Electric Power, Zhengzhou, 450046, China; Department of Biological and Agricultural Engineering, Texas A\&M University, Scoates Hall, Room\#322, College Station, TX 77843; Global Development \& Innovative Services, FL 33774

Additional index words. drip irrigation, greenhouse climate control, humid, hot, environment, spatial variation, temporal variation, wind speed

Abstract. Ventilation and soil moisture influence greenhouse cultivation. Experiments
were conducted at Xinxiang Irrigation Research Base of the Chinese Academy of
Agricultural Sciences, Henan Province, China, to identify how ventilation and irriga-
tion affected the greenhouse microenvironment. To develop ventilation and irrigation
protocols that increase crop yield and improve the quality of drip-irrigated tomatoes
grown in the greenhouse, three ventilation modes (T1, T2, and T3) were developed by
opening vents in different locations in a completely randomized pattern. T1 had open
vents on the north wall and roof of the greenhouse. T2 had open vents on the north
and south walls and the roof. T3 had open vents on the north and south walls. Three
irrigation treatments $(W 1, W 2$, and W3) were designed based on the accumulated
water surface evaporation $\left(E_{p}\right)$ of a standard 20 -cm evaporation pan. The irrigation
quantities were $0.9 \times E_{p}(W 1), 0.7 \times E_{p}(W 2)$, and $0.5 \times E_{p}(W 3)$. The spatial and tempo-
ral distributions of temperature and humidity were analyzed for different combina-
tions of ventilation and irrigation to identify their effects on tomato yield and fruit
quality. Major results were as follows: 1$)$ In addition to solar radiation, ventilation
had an important influence on $E_{p}$ and, on a daily scale, ventilation had a significant
effect on $E_{p}(P<0.05)$. 2$)$ Ventilation had a significant effect on indoor wind speed,
but the effect varied during different growth stages. During the flowering and fruit
setting stage, wind speed for $T 2$ significantly differed from those of T1 and T3 $(P<$
$0.01)$. During the harvest stage, the three ventilation treatments had significantly dif-
ferent effects $(P<0.01)$. A correlation analysis showed high correlation between T2
wind speed and T3 wind speed $(R=0.831)$, but low correlation between T2 wind
speed and $T 1$ wind speed $(R=0.467)$. 3$)$ The effect of ventilation on greenhouse
humidity and temperature was greater than the effect of irrigation. The differences in
air temperature among various combined treatments of ventilation and irrigation
were significant for the flowering and fruiting stages $(P<0.05)$ but they were not
Greenhouse cultivation is increasing in scale in line with other developments in modern agriculture that have made agriculture a major driver of economic development (Gong et al., 2020; Liu et al., 2018; Wang et al., 2020). Control of the greenhouse environment through management of the microclimate and controlled irrigation promotes healthy crop growth, increased crop yield, and increased fruit quality (Liu et al., 2019b; Shamshiri et al., 2018; Wang and Zhou, 2017). There is an urgent need for a sciencebased protocol to regulate the greenhouse environment and manage greenhouse irrigation to ensure the health and sustainability of greenhouse cultivation in China (Orgaz et al., 2005; Peng et al., 2018).

The greenhouse microenvironment has important effects on crop growth, crop yield, and fruit quality. For example, excessively high temperatures cause pollen damage and leaf wilting, thus reducing yield (Harel et al., 2014), whereas excessively low temperatures affect enzyme activity and inhibit plant growth (Vanthoor et al., 2011). Excessively high humidity in a greenhouse reduces plant transpiration and causes flower rot (Huang et al., 2011) and, over the long term, reduces fruit quality (Choi et al., 1997). Control of ventilation is critical to regulating the greenhouse environment because ventilation can affect temperature, humidity, wind speed, and other meteorological parameters in the greenhouse (Yuan et al., 2015), thereby affecting crop growth, fruit development, crop yield, and fruit quality (Traore et al., 2020; Zhang et al., 2019a). Chu et al. (2017) showed that different ventilation regimes cause different convection patterns that influence the indoor microenvironment. Benni et al. (2016) found that the spatial distributions of greenhouse temperature and humidity were greatly affected by ventilation. Indoor air was relatively still in an unvented greenhouse, and there were only small spatial differences in temperature and humidity. When the greenhouse was vented to increase airflow, the indoor temperature distribution showed a distinct gradient from higher temperatures in the south to lower temperatures in the north of the greenhouse, whereas the spatial distribution of relative humidity showed the inverse (a high-low gradient from north to south) ( $\mathrm{Su}, 2016)$. Kong et al. (2009) showed that air movement at the seedling stage increased stem diameter, leaf thickness, plant dry weight, and chlorophyll content, all of which are critical to yield. However, some studies have shown that wind speed in a greenhouse can increase ineffective crop transpiration and reduce yield. For example, studies have shown that when wind speed in a greenhouse was 0.8 to $1.0 \mathrm{~m} / \mathrm{s}$, the leaf area index, stomatal conductance, transpiration rate, and photosynthesis increased significantly, resulting in earlier plant ripening by $2 \mathrm{~d}$, an $11.1 \%$ increase in total sugar content, and a $24.4 \%$ increase in yield ( $\mathrm{Li}$ et al., 2008; Yang et al., 2007). It is clear that the use of ventilation to regulate the internal greenhouse microclimate increases crop yield 
significant for the late harvest stage $(P>0.05)$. There were significant differences in humidity on sunny days $(P<0.01)$, but no significant differences on cloudy or rainy days $(P>0.05)$. Air temperature at $2 \mathrm{~m}$ was greater than canopy temperature, but humidity at $2 \mathrm{~m}$ was less than that at canopy level. 4) Irrigation water quantity was positively correlated with tomato yield and negatively correlated with the fruit quality indicators total soluble solids, vitamin $C$ content, organic acid content, and soluble sugars content. Ventilation had an effect primarily during the harvest period; it had no significant effect on yield $(P>0.05)$. However, it had a significant effect on vitamin $C$ content and the sugar:acid ratio $(P<0.01)$. The combination treatment of $T 2 W 2$ is recommended as the optimal treatment for greenhouse tomatoes using drip irrigation to produce an optimal combination of crop yield and fruit quality. This study provides theoretical and technical support for the improvement of greenhouse climate control by optimizing greenhouse ventilation and irrigation techniques to promote tomato yield and improve fruit quality.

and fruit quality. However, at present, natural ventilation of a greenhouse is based mainly on the farmer's experience, and the difficult task of developing a scientifically based effective ventilation management protocol remains incomplete.

$\mathrm{Li}$ et al. (2017) found that water was an important factor in determining crop growth, fruit development, crop yield, and fruit quality. A large quantity of irrigation water can promote plant growth and increase yield, but it will also increase water consumption and reduce fruit quality; a small irrigation quantity will constrain plant growth and yield, but it will also reduce water consumption and increase fruit quality. Liu et al. (2010) found that an excessive water deficit destroyed plant tissue by inhibiting stem flow, thus affecting the normal physiological processes of crop growth. Xie and Cai (2013) investigated the effects of drip irrigation under mulch on plant growth, crop yield, fruit quality, and water use efficiency for greenhouse muskmelon in Guanzhong. They found that using $75 \%$ of field capacity as the lower limit of the irrigation quantity increased the mass fractions of soluble solids, total soluble sugars, soluble proteins, and organic acids in fruit, and that this was the optimal irrigation quantity. Hooshmand et al. (2019) and Liu et al. (2019a) investigated irrigation protocols for greenhouse crops. During a preliminary study, they set different soil moisture levels and found that soil moisture had a significant effect on the crop yield and fruit quality of a greenhouse crop.

Tomato plants are sensitive to temperature and humidity as well as soil moisture. Thus

Received for publication 8 June 2021. Accepted for publication 16 June 2021

Published online 9 August 2021.

This research was supported by the National Natural Science Foundation of China (51709110, 51909092, 51809094, and 51779093), the National Key Research and Development Program of China (2017YFC0404402), the Foundation for University Young Key Scholar of Henan Province (2020GG JS100), and Key Scientific Research Projects of Higher Education Institutions in Henan Province (21A570003).

L.Z. is the corresponding author. E-mail:

zhanglei@ncwu.edu.cn.

This is an open access article distributed under the CC BY-NC-ND license (https://creativecommons. org/licenses/by-nc-nd/4.0/). the effects of both ventilation and moisture must be fully considered in greenhouse cultivation. Most current studies consider only the effects of a single factor; therefore, there are few literatures concerning multifactor effects, particularly of ventilation and moisture, on the greenhouse microclimate, crop yield, and fruit quality. As a result, there is no widely accepted combination of ventilation and irrigation that optimizes greenhouse crop production. During this study, we combined water and ventilation treatments to investigate the spatial distributions of humidity and heat in a greenhouse as they affected crop yield and fruit quality for a commonly grown local tomato variety using drip irrigation. This research provides technical guidance for optimizing greenhouse ventilation and irrigation protocols to promote tomato yield and quality.

\section{Materials and Methods}

\section{Experimental site}

This study was conducted in a solar greenhouse at the Xinxiang Irrigation Research Base of the Chinese Academy of Agricultural Sciences (lat. $35^{\circ} 9^{\prime} \mathrm{N}$, long. $113^{\circ} 47^{\prime} \mathrm{E}, 78.7 \mathrm{~m}$ above mean sea level) from March to July 2019. The average annual rainfall at the site is 548.3 $\mathrm{mm}$. The average annual evaporation is 1908.7 $\mathrm{mm}$. The average annual temperature is $14.1^{\circ} \mathrm{C}$. The average annual hours of sunshine are 2398.8 $\mathrm{h}$. The frost-free period is $200.5 \mathrm{~d}$. The climate is warm temperate continental monsoon. The greenhouse used for the experiment covered an area of $510 \mathrm{~m}^{2}$ (60 $\mathrm{m}$ long and $8.5 \mathrm{~m}$ wide), and it was dug $0.5 \mathrm{~m}$ into the soil. The longitudinal axis was east-west. Soil in the greenhouse was covered with 0.2-mm-thick dripless polyethylene film, and a 5-cm-thick layer of thermal insulation was placed on top of that film. The side and rear foundation walls had $60 \mathrm{~cm}$ of insulation attached to ensure that the temperature in the greenhouse was $\geq 20^{\circ} \mathrm{C}$. The soil in the experimental area was a chalk composite $(10.49 \%$ clay, $80.76 \%$ powder, and $8.75 \%$ sand) with an average bulk weight of $1.6 \mathrm{~g} / \mathrm{cm}^{3}$ in a layer 100 $\mathrm{cm}$ deep; the field capacity was $23.91 \%$ (water content $\times$ mass). There were three ventilation ports in the greenhouse located centrally at the top $(60 \mathrm{~m} \times 0.3 \mathrm{~m})$ and in the south $(60 \mathrm{~m} \times 1.5$ $\mathrm{m})$ and north $(20 \mathrm{~cm} \times 20 \mathrm{~cm})$ walls, resulting in a total of 19 adjustable vents.

\section{Experimental design}

The experiment was conducted in a solar greenhouse, which was subdivided laterally into three separate partitions of equal area using opaque polycarbonate panels. A different ventilation treatment was applied to each partition. Treatment T1 consisted of opening the north wall vents and the top window vents simultaneously; T2 consisted of opening the north wall vents, south wall vents, and top vents; and T3 consisted of opening the north wall vents and south wall vents. Three irrigation treatments, W1, W2, and W3, were applied to each partition. Each irrigation treatment consisted of three applications on three adjacent experimental plots. The irrigation time and water quantity were determined by the cumulative evaporation $E_{p}$ using a $20-\mathrm{cm}$ standard evaporation pan in each partition. Irrigation commenced when $E_{p}$ reached $20 \pm$ $2 \mathrm{~mm}$. The irrigation quantities were $0.9 \times E_{p}$ (W1), $0.7 \times E_{p}(\mathrm{~W} 2)$, and $0.5 \times E_{p}(\mathrm{~W} 3)$. Each irrigation plot was surrounded by plastic film dug to a depth of $60 \mathrm{~cm}$ to prevent lateral water seepage.

The experiment used the greenhouse tomato cultivar Fire Phoenix. The plant seeds were sown on 5 Jan. 2019 an transplanted on 21 Mar.; fruit were picked eight times from 29 May onward. Ridge planting was used with ridges $8 \mathrm{~m}$ long and $0.5 \mathrm{~m}$ wide. Two rows were planted in each ridge. Row spacing was $50 \mathrm{~cm}$, and plant spacing was $30 \mathrm{~cm}$. Drip irrigation was applied under the mulch. Drip orifices were spaced at the same intervals as those used for plant spacing. A drip irrigation hose (designed flow rate $1.1 \mathrm{~L} / \mathrm{h}$ ) was laid out along each plant row.

The tomato plants were considered to have three growth stages: a seedling stage (21 Mar.-13 Apr.), a flowering and fruit setting stage (14 Apr.-29 May), and a harvest stage (30 May-6 July). All three partitions were uniformly irrigated with $20 \mathrm{~mm}$ of water after planting to ensure the survival of seedlings. There was no other irrigation during the first 3 weeks to avoid leggy tomato seedlings. Irrigation was withheld until soil moisture content in the upper $40 \mathrm{~cm}$ of the soil layer reached $60 \%$ of field capacity. Irrigation was ceased 1 week before the end of the experiment. The ventilation treatments were applied concurrently with the irrigation treatments. The vents were usually open from 08:00 HR to 18:00 HR, but this varied in cases of extreme weather, such as heavy rain or gales.

\section{Experimental parameters and methods}

Meteorological parameters. Meteorological factors inside the greenhouse were recorded by an automatic climate monitoring system. Data gathered included total radiation $R_{a}$ (LI200X; Campbell Science Inc., Logan, UT), air temperature $\left(T_{i}\right)$, and humidity $\left(R H_{i}\right)$ (U23-002A; Onset Hobo Inc., Cape Cod, MA), and wind speed $(u)$ (WindSonic; Gill Inc., Newcastle Upon Tyne, UK). All meteorological data were automatically recorded by a data logger (CR1000; Campbell Science Inc.) at $30-\mathrm{min}$ intervals. The sensors were 
one air temperature and humidity sensor $(2.0$ $\mathrm{m}$ above the ground with resolution of $0.02{ }^{\circ} \mathrm{C}$ and $0.05 \%$ ), one two-dimensional wind sensor (30 $\mathrm{cm}$ above the canopy, with resolution of $0.01 \mathrm{~m} / \mathrm{s})$, and one radiation sensor $(30 \mathrm{~cm}$ above the canopy, with resolution of 0.001 $\mathrm{MJ} / \mathrm{m}^{2} / \mathrm{d}$ ). Sensors were placed at the center of each partition. In addition, three air temperature and humidity sensors were placed in each partition $30 \mathrm{~cm}$ above the crop canopy for each irrigation treatment. These sensors were adjusted as canopy height increased.

Surface evaporation. Surface evaporation in each partition was measured using a standard evaporating pan (ADM7; Zhonghuan Tig Inc., Tianjin, China) with a $20-\mathrm{cm}$ diameter and 11-cm depth. The evaporating pan was placed at the center of the partition 30 $\mathrm{cm}$ above the canopy; its position was adjusted as canopy height changed. The evaporating pan was measured daily during the period from 0700 to $0800 \mathrm{HR}$. Distilled water in the evaporating pan was replaced to a depth of $20 \mathrm{~mm}$ after each measurement.

Yield and quality. Fruit were picked eight times during the experiment. During the harvest stage, 20 tomato plants in the middle of each ridge were identified and marked as yield measurement plants. The tomato number per treatment was recorded for each fruit picking, and the tomato weight per treatment was measured and recorded using an electronic scale with an accuracy of $0.001 \mathrm{~kg}$. Six fruits that had blossomed and set fruit on the same day were randomly selected from each treatment as quality-measurement plants. Fruit hardness was measured by a fruit hardness tester (FHM-5; Takemura Electric Works Ltd., Tokyo, Japan). The total soluble solids (TSS) content was measured with a handheld sugar meter. The vitamin $\mathrm{C}$ content $\left(V_{C}\right)$ was determined by 2, 6-dichlorophenol indophenols titration. The organic acid (OA) content was measured by alkali titration. The soluble sugar content (SSC) was measured by anthrone colorimetry.

Data processing. Data were processed, analyzed, and charted using Excel software (Microsoft, Redmond, WA). An analysis of variance was performed using SPSS software
(IBM, Armonk, NY). Significance was determined using Duncan's new multiple range test.

\section{Results}

Solar radiation, surface evaporation, and wind speed

Figure 1 shows the $R_{a}$ and $E_{p}$ for different ventilation treatments during the growth period. Variations in $E_{p}$ for the three ventilation treatments were consistent with the variations in $R_{a}$. There was no significant difference in evaporation among different treatments over the entire growth period $(P>0.05)$ (Fig. 1B). The $E_{p}$ reached a maximum $(5.9 \mathrm{~mm})$ with $\mathrm{T} 2$ on 6 July, when $R_{a}$ was $18.72 \mathrm{MJ} / \mathrm{m}^{2} / \mathrm{d}$. The $E_{p}$ reached a minimum $(0.1 \mathrm{~mm})$ with both $\mathrm{T} 1$ and T3 on $22 \mathrm{Apr}$., and $R_{a}$ reached a minimum $\left(0.59 \mathrm{MJ} / \mathrm{m}^{2} / \mathrm{d}\right)$ during the flowering and fruit setting stage (Fig. 1A). This showed that $R_{a}$ was the main factor that influenced surface evaporation. The $E_{p}$ was greater with $\mathrm{T} 2$ than with T1 or T3 in windy weather. For example, the $E_{p}$ of T1 on 15 June was $4.5 \mathrm{~mm}$, which was $18.4 \%$ greater than the $E_{p}$ with $\mathrm{T} 1$ and $15.8 \%$ greater than the $E_{p}$ with T3. This indicated that ventilation was also an important influence on surface evaporation and that, in the case of good ventilation, wind pressure outside the greenhouse made a significant difference in the $E_{p}$ in the greenhouse with different ventilation treatments $(P<0.05)$.

\section{Wind speed during different growth stages}

Figure 2 shows wind speed, $u$, in the greenhouse for different growth stages. Overall, trends were consistent across the three partitions, but there were differences during the three growth stages. During the flowering and fruiting stage, $u$ was as follows: T2 $>\mathrm{T} 1$ $>$ T3 (Fig. 2A). There was no significant difference in $u$ between $\mathrm{T} 1$ and $\mathrm{T} 3$, with respective mean values of $0.095 \mathrm{~m} / \mathrm{s}$ and $0.091 \mathrm{~m} / \mathrm{s}$ $(P>0.05)$. The mean value of $u$ with $\mathrm{T} 2$ was $0.134 \mathrm{~m} / \mathrm{s}$, with a maximum value of 0.449 $\mathrm{m} / \mathrm{s}$, which was significantly different from the values of $u$ with T1 and $u$ with T2 $(P<$ $0.01)$. During the harvest stage, $u$ was as follows: $\mathrm{T} 2>\mathrm{T} 3>\mathrm{T} 1$ (Fig. $2 \mathrm{~B}$ ). The mean value of $u$ with T2 was $0.223 \mathrm{~m} / \mathrm{s}$, which was $79.8 \%$ greater than $u$ with $\mathrm{T} 3$ and $123.1 \%$ greater than $u$ with $\mathrm{T} 1$. There were also significant differences in $u$ among the three ventilation treatments $(P<0.01)$.

A correlation analysis showed a high correlation between $u$ with $\mathrm{T} 2$ and $u$ with $\mathrm{T} 3$ $(R=0.831)$, and a low correlation between $u$ with $\mathrm{T} 2$ and $u$ with $\mathrm{T} 1(R=0.467)$, which indicated that opening the horizontal vent on the south wall increased gas exchange more than opening the roof vent, and that in windy conditions, $u$ could change suddenly with both $\mathrm{T} 2$ and $\mathrm{T} 3$.

\section{Changes in air temperature and humidity under different ventilation treatments}

Figure 3 shows crop canopy temperature, $T_{i}$, and relative humidity, $R H_{i}$, for each irrigation treatment under the three ventilation treatments. Both $T_{i}$ and $R H_{i}$ with $\mathrm{W} 1$ were as follows: $\mathrm{T} 3>\mathrm{T} 1>\mathrm{T} 2 . T_{i}$ for the entire growth period with $\mathrm{W} 2$ was ordered as $\mathrm{T} 3>$ $\mathrm{T} 1>\mathrm{T} 2$, but $R H_{i}$ for the flowering and fruiting stage was ordered as $\mathrm{T} 1>\mathrm{T} 3>\mathrm{T} 2 . T_{i}$ with $\mathrm{W} 3$ was ordered as $\mathrm{T} 1>\mathrm{T} 3>\mathrm{T} 2$, but $R H_{i}$ with $\mathrm{W} 3$ was ordered as $\mathrm{T} 3>\mathrm{T} 1>\mathrm{T} 2$. For the entire growth period, $T_{i}$ and $R H_{i}$ were both lower with $\mathrm{T} 2$ than with $\mathrm{T} 1$ or T3. The lowest value of $T_{i}$ was $15.983^{\circ} \mathrm{C}$ for the combined treatment $\mathrm{T} 2 \mathrm{~W} 1$, which was $2.3 \%$ less than that for T2W2 and 3.1\% lower than that for $\mathrm{T} 2 \mathrm{~W} 3$. The minimum value of $R H_{i}$ was $43.7 \%$ for T2W2, which was $5.7 \%$ less than that for $\mathrm{T} 2 \mathrm{~W} 1$ and $6.2 \%$ less than that for T2W3. Over the entire growth period, both moisture and ventilation affected canopy $T_{i}$ and $R H_{i}$, but the effect of humidity was less than the effect of ventilation.

Figure 4 shows $T_{i}$ and $R H_{i}$ at a height of $2 \mathrm{~m}$ in the greenhouse over the course of the growth period. The variation in $T_{i}$ at $2 \mathrm{~m}$ was consistent across the three ventilation treatments and was ordered as $\mathrm{T} 3>\mathrm{T} 1>\mathrm{T} 2$. There was a significant difference in $T_{i}$ at $2 \mathrm{~m}$ among the three ventilation treatments $(P<0.05)$ during the flowering and fruiting stage. The average $T_{i}$
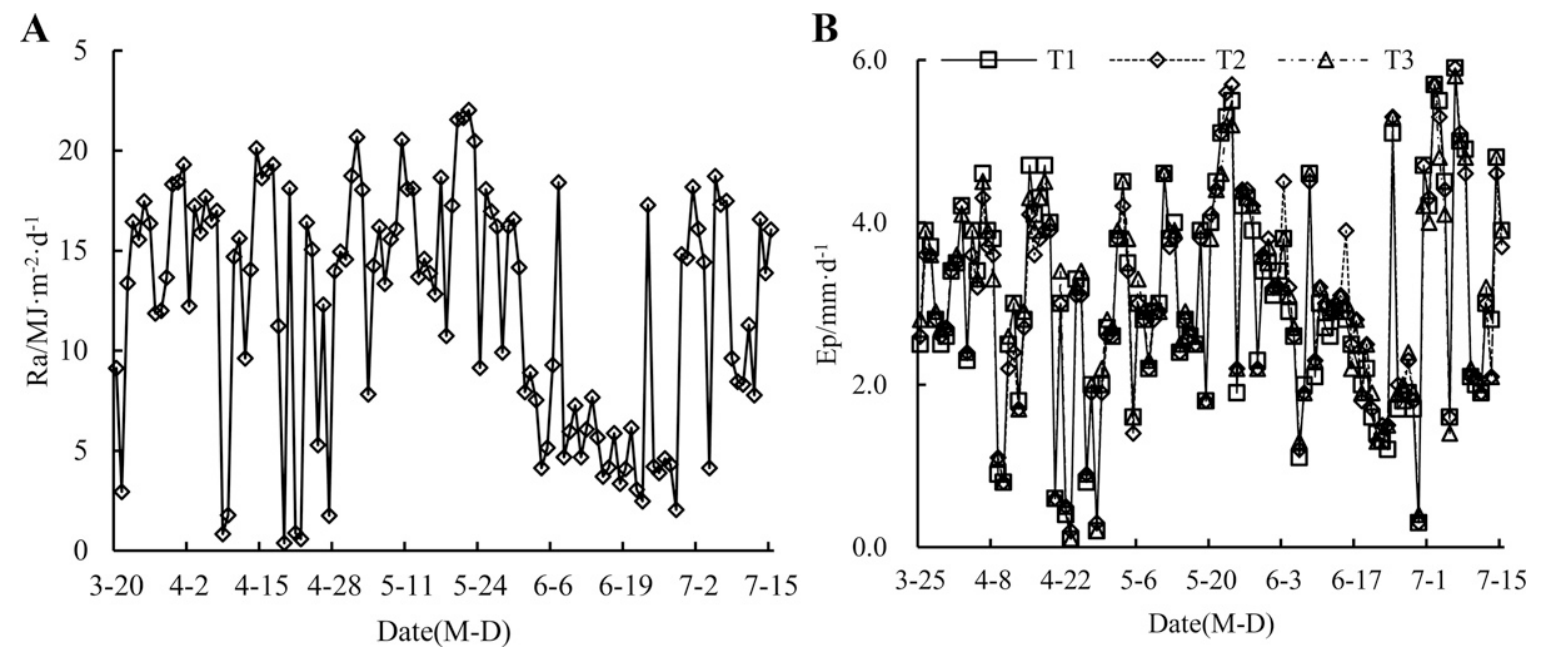

Fig. 1. Changes in solar radiation (A) and water surface evaporation (B). 
A

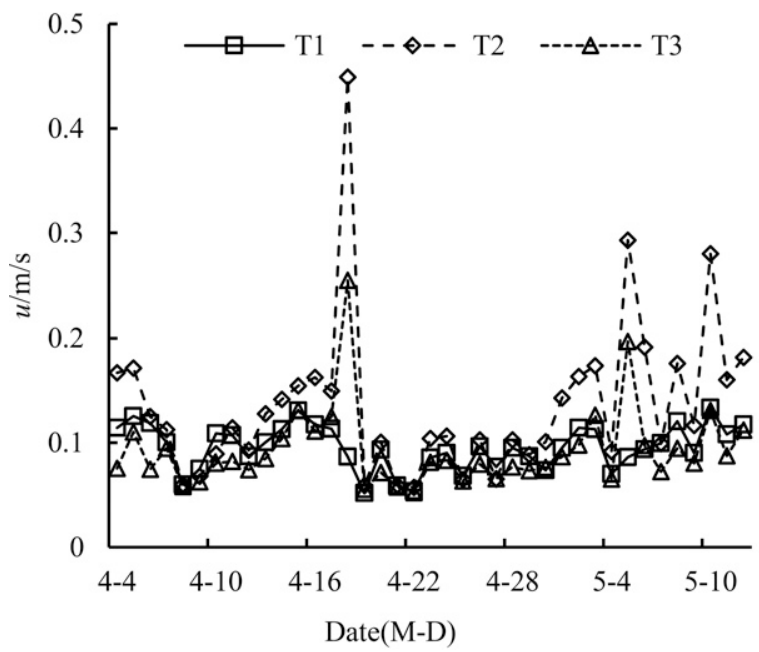

B

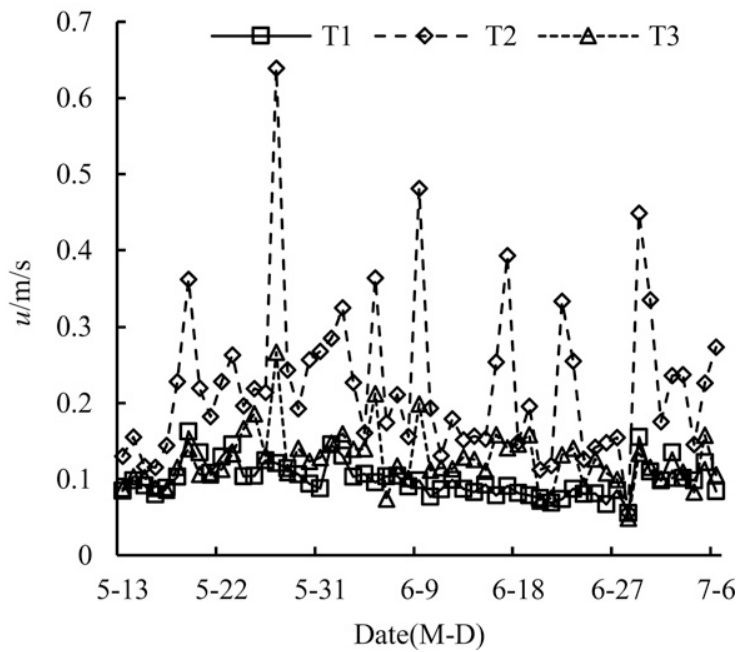

Fig. 2. Changes in the greenhouse wind speed during the flowering and fruiting stage (A) and the mature and picking stage (B).

with $\mathrm{T} 2$ was $22.0^{\circ} \mathrm{C}$, which was $7.0 \%$ less than that with $\mathrm{T} 1$ and $7.2 \%$ less than that with $\mathrm{T} 3$. During the harvest stage, when temperature increased, ventilation had little cooling effect. The difference was not significant $(P>0.05)$, and $T_{i}$ was ordered as $\mathrm{T} 3>\mathrm{T} 1>\mathrm{T} 2$.

$R H_{i}$ at $2 \mathrm{~m}$ in the three partitions was also ordered as $\mathrm{T} 3>\mathrm{T} 1>\mathrm{T} 2$. The maximum $R H_{i}$ occurred with T3 $(57.73 \%)$, and the minimum $R H_{i}$ occurred with T2 $(46.71 \%)$; there was no significant difference among treatments over the course of the entire growth period $(P>$ $0.05)$. Cooling caused by ventilation was greatly affected by weather conditions. For example, during an unbroken period of sunny days (6 June-16 June), the average $R H_{i}$ with
T2 was $49.6 \%$, which was $7.5 \%$ less than that with $\mathrm{T} 1$ and $10.1 \%$ less than that with $\mathrm{T} 3$. The differences were significant $(P<0.01)$. However, on cloudy or rainy days (such as 20 June), $R H_{i}$ at $2 \mathrm{~m}$ inside the greenhouse and outdoor relative humidity were both more than $85 \%$; therefore, ventilation did not reduce humidity.
A

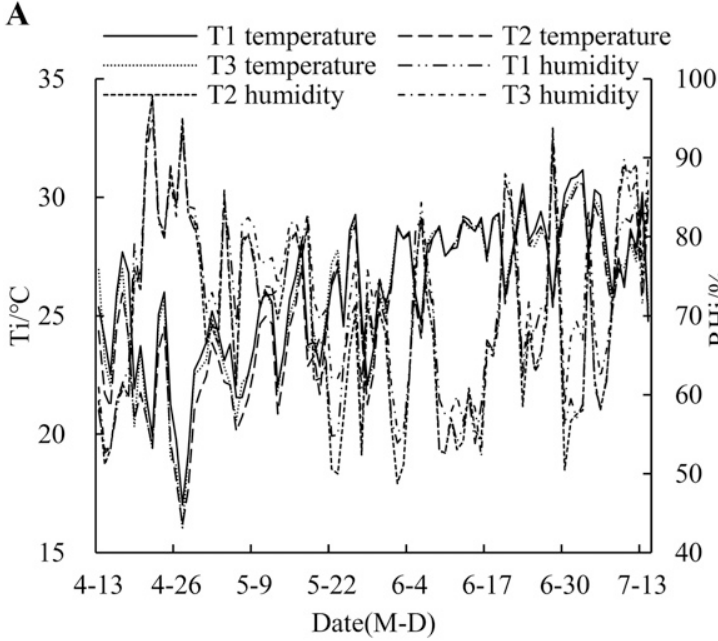

C

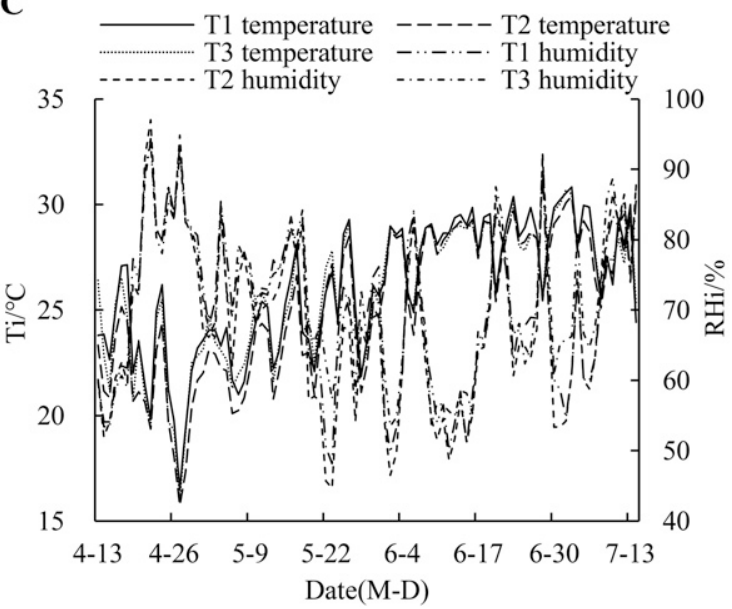

B

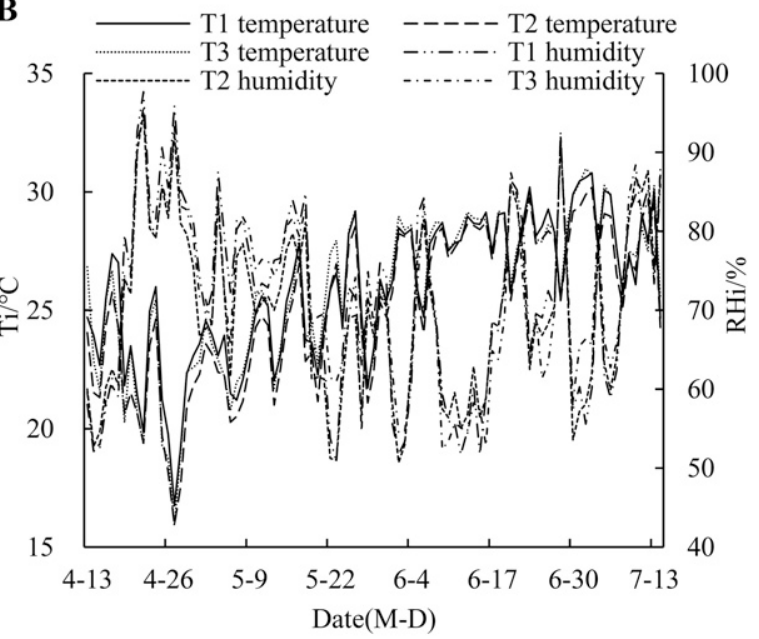

Fig. 3. Changes in canopy temperature and humidity with T1 (A), T2 (B), and T3 (C). 


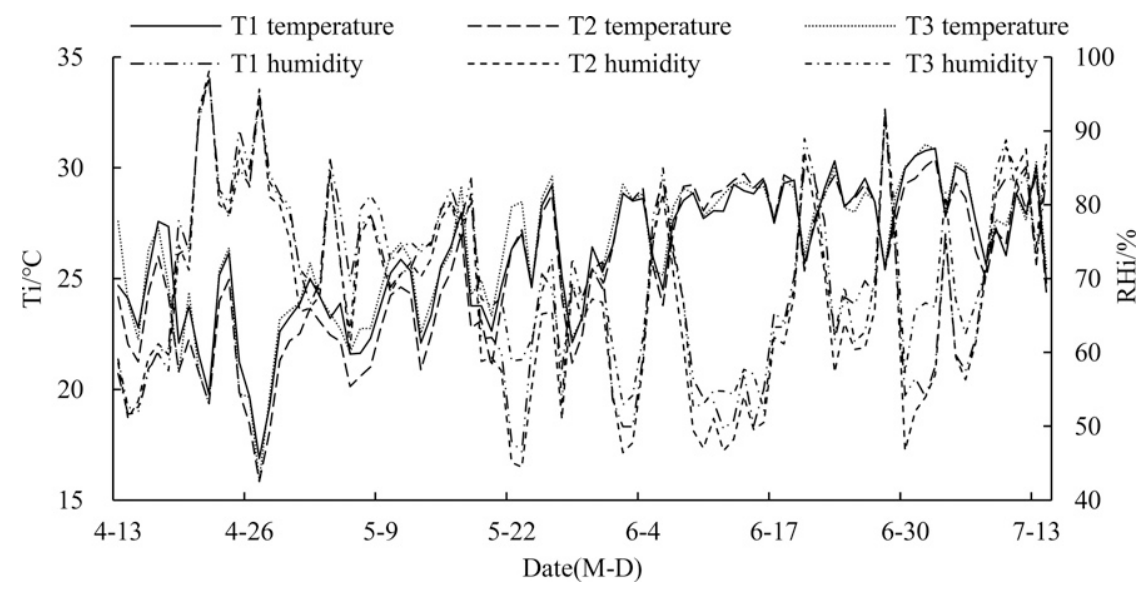

Fig. 4. Temperature and humidity changes at $2 \mathrm{~m}$ with different ventilation modes.

Changes in vertical air temperature and humidity for different ventilation modes

Figure 5 shows $T_{i}$ at canopy height and $R H_{i}$ at $2 \mathrm{~m}$ for the three ventilation treatments. It could be seen that the variation in $T_{i}$ at canopy height over the entire growth period was consistent with the variation in $T_{i}$ at $2 \mathrm{~m}$, and that $T_{i}$ at $2 \mathrm{~m}$ was always greater than $T_{i}$ at canopy height. Differences between the two were greatest with treatment T2. For example, during the period 7 June to 11 June
(Fig. 5B), the average $T_{i}$ at $2 \mathrm{~m}$ was $4.8 \%$ greater than the average $T_{i}$ at canopy height, and the difference in temperature reached a maximum of $1.5^{\circ} \mathrm{C}$. This difference in vertical temperature was significant $(P<0.05)$. When there was little effective ventilation, there was no significant difference in the vertical temperatures with $\mathrm{T} 1$ and $\mathrm{T} 3(P>0.05)$ (Figs. 5A and C).

$R H_{i}$ at canopy height was consistent with $R H_{i}$ at $2 \mathrm{~m}$ with all three ventilation treatments, and $R H_{i}$ at canopy height was greater than $R H_{i}$ at $2 \mathrm{~m}$. The difference among them was greatest with treatment T2. For example, during the period 9 June to 22 June (Fig. 5B), the average $R H_{i}$ at canopy height was $12.1 \%$ greater than the $R H_{i}$ at $2 \mathrm{~m}$. The difference in relative humidity in the greenhouse was significant $(P<$ $0.01)$. There were no significant differences in relative humidity with treatments $\mathrm{T} 1$ and $\mathrm{T} 3$ over the course of the entire growth period $(P>$ $0.05)$ (Figs. 5A and C). Ventilation clearly had a great effect on the vertical distribution of humidity and temperature in the greenhouse.

\section{Variations in air temperature and humidity with different irrigation treatments}

Figure 6 shows $T_{i}$ at canopy height and $R H_{i}$ at canopy height with different irrigation treatments. $T_{i}$ for the three ventilation treatments was ordered as $\mathrm{W} 3>\mathrm{W} 1>\mathrm{W} 2$ for the entire growth period. $R H_{i}$ with treatment $\mathrm{T} 1$ was ordered as $\mathrm{W} 2>\mathrm{W} 3>\mathrm{W} 1$ for the entire growth period (Fig. 6A). $R H_{i}$ with treatment T2 was ordered as $\mathrm{W} 1>\mathrm{W} 2>\mathrm{W} 3$ during the flowering and fruiting stage and as $\mathrm{W} 2>\mathrm{W} 1$ $>\mathrm{W} 3$ during the harvest stage (Fig. 6B). $R H_{i}$ with the $\mathrm{T} 3$ treatment was ordered as $\mathrm{W} 1>$ W2 $>$ W3 (Fig. 6C). The effects of the irrigation treatment on temperature at canopy height
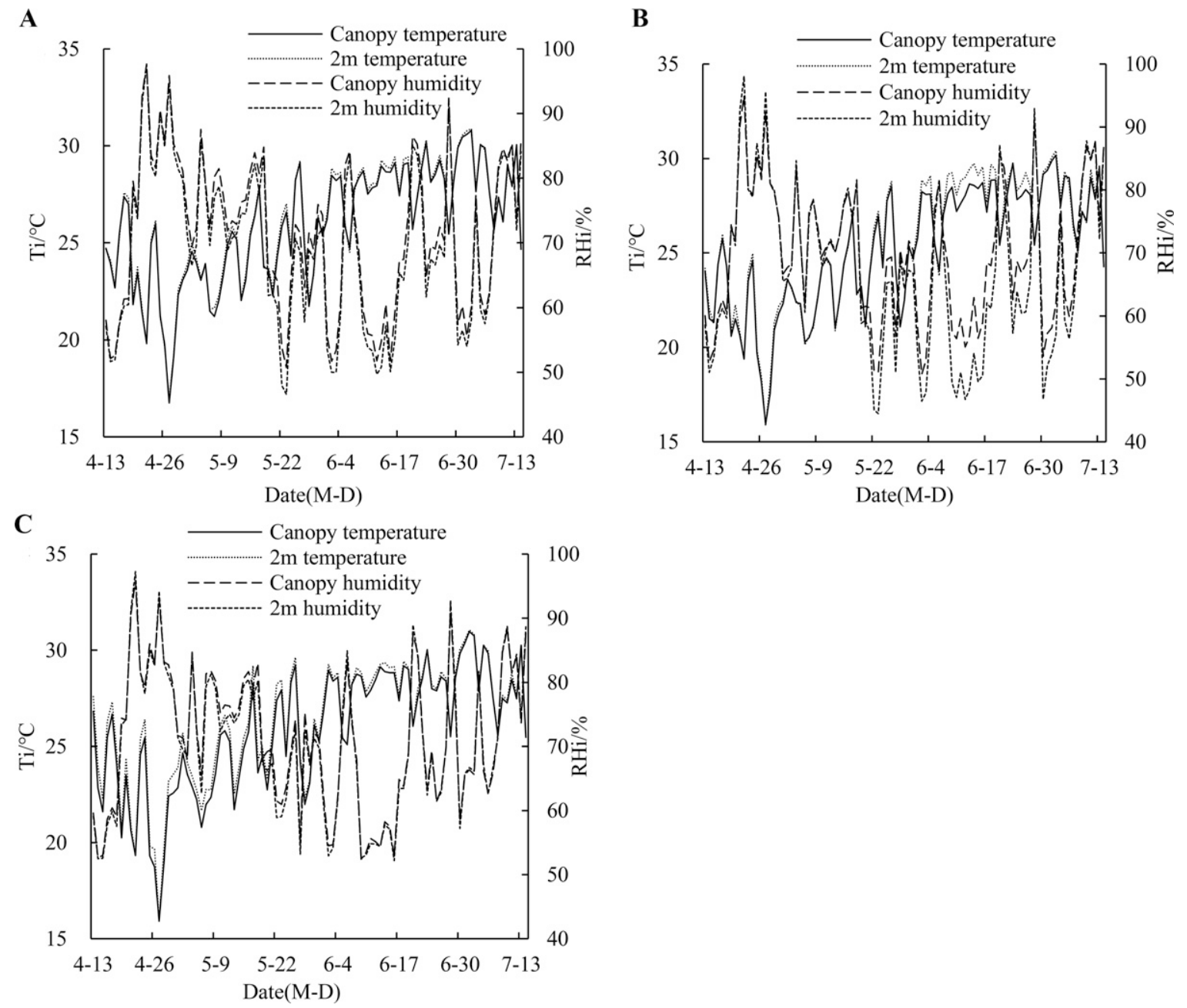

Fig. 5. Comparison of temperature and humidity between the canopy and $2 \mathrm{~m}$ with $\mathrm{T} 1$ (A), T2 (B), and T3 (C). 


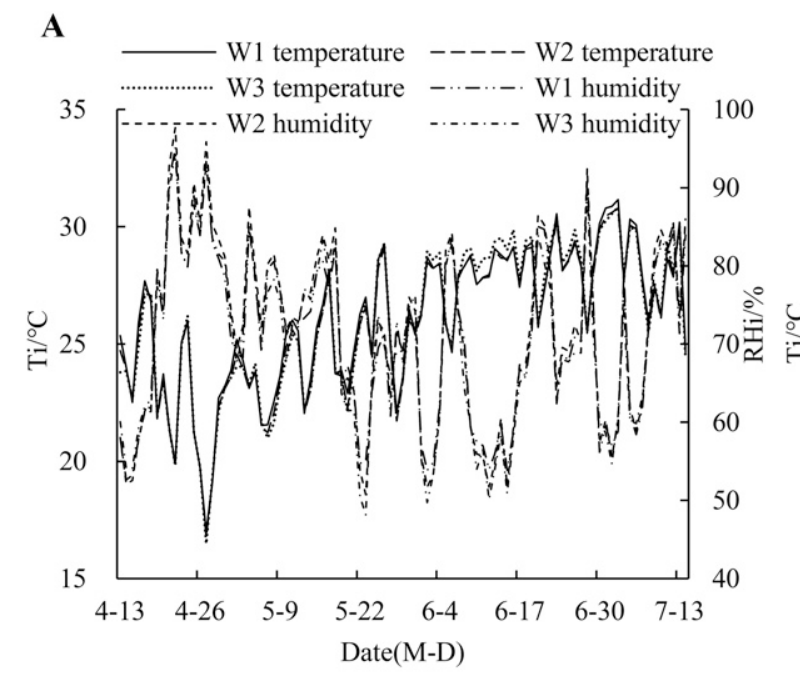

B
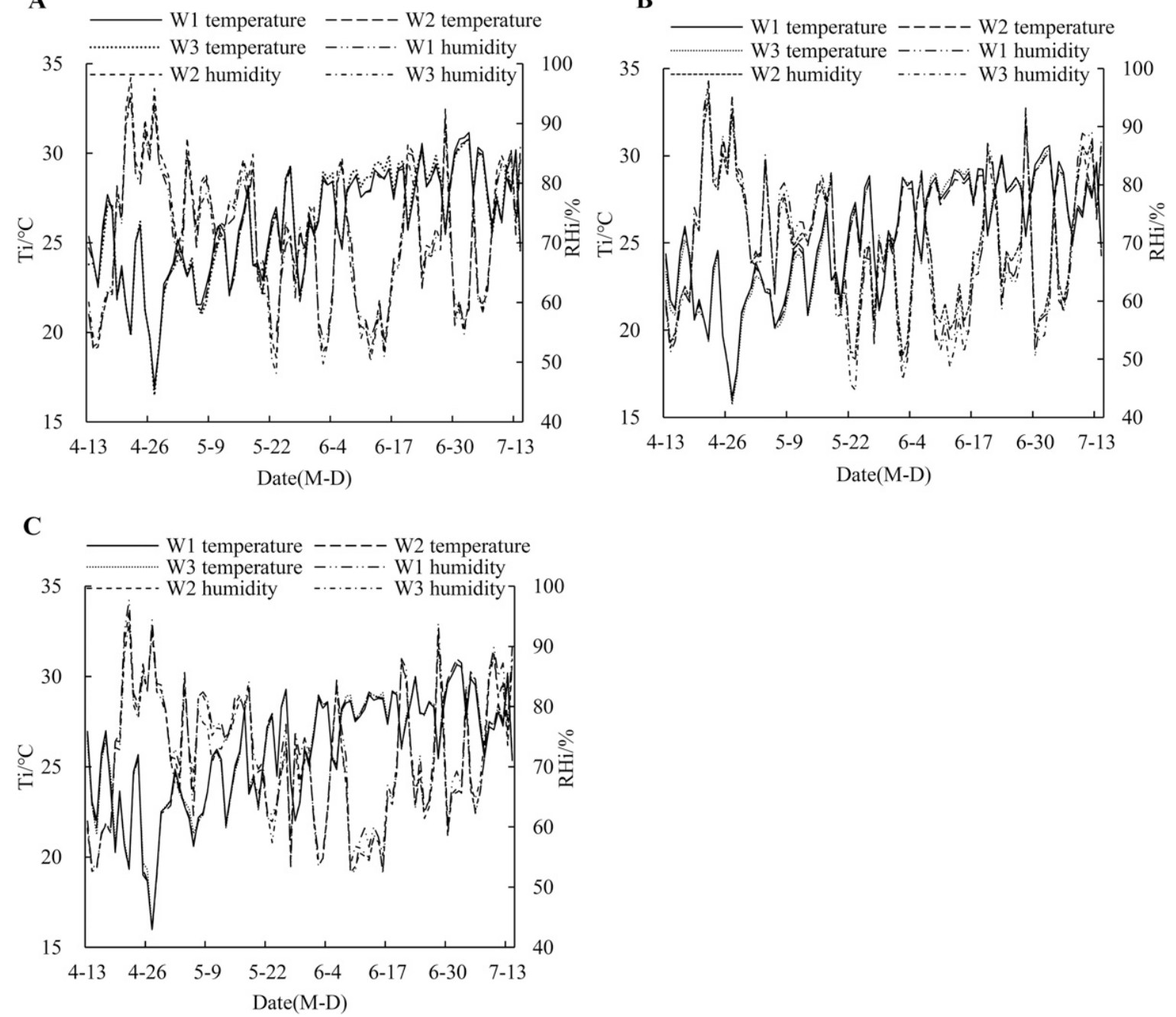

Fig. 6. Temperature and humidity with different water treatments with T1 (A), T2 (B), and T3 (C).

and relative humidity at canopy height were small, and differences were not significant $(P>0.05)$.

\section{Effects of different ventilation and moisture combinations on tomato yield and quality}

Tomatoes were harvested eight times during the harvest period. The harvested fruit count and yield were both low during the early (29 May-13 June) and late (27 June-15 July) pickings, and both were high during the middle period (14 June-26 June). The yields with $\mathrm{T} 1, \mathrm{~T} 2$, and $\mathrm{T} 3$ during the middle period were $53.2 \%, 58.2 \%$, and $65.5 \%$, respectively, of the total yield.

Different combinations of ventilation and irrigation treatments had significant effects on tomato yield. Figure 7 shows that for the same irrigation treatment, picking during the early period of the harvest stage with T1 produced $48.6 \%$ of the total yield, but yields from the middle and late harvest periods with $\mathrm{T} 1$ were significantly lower than those with T2 and T3 $(P<0.05)$. During the middle and late harvest periods, the average yield of tomatoes was $117.6 \mathrm{t} / \mathrm{ha}$ with $\mathrm{T} 2$; this was $21.0 \%$ greater than that with $\mathrm{T} 1$ and $3.0 \%$ greater than that with T3. Among them, the yields in the middle and late harvest periods with treatment T2W1 were $83.8 \mathrm{t} / \mathrm{ha}$ and $47.2 \mathrm{t} / \mathrm{ha}$, respectively, which were significantly greater than the yields with other treatments $(P<0.05)$. Figure 8 shows that across all three ventilation treatments, tomato yields with irrigation treatments $\mathrm{W} 1, \mathrm{~W} 2$, and $\mathrm{W} 3$ were in the ranges of 140 to $145.4,130.1$ to 135 , and 122.7 to 124.7 $\mathrm{t} / \mathrm{ha}$, respectively, and in all three partitions were ordered as $\mathrm{W} 1>\mathrm{W} 2>\mathrm{W} 3$. The difference in total yield of the three irrigation treatments was most significant with $\mathrm{T} 2(P<$ $0.05)$. Overall, the irrigation treatment had a significant effect on tomato yield, whereas the ventilation mode mainly affected the number of tomatoes picked at each picking but had no significant effect on total yield $(P>0.05)$.

\section{Effects of ventilation and irrigation combinations on tomato quality}

Table 2 shows the values of the quality indexes TSS, VC, OA, SSC, and SAR for tomato fruits under different ventilation and irrigation treatments. For the same ventilation mode, irrigation quantity had no significant effect on SAR $(P>0.05)$ but was significantly negatively correlated with TSS, VC,
$\mathrm{OA}$, and $\mathrm{SSC}(P<0.01)$. The values of TSS, $\mathrm{VC}, \mathrm{OA}$, and SSC with treatment W3 were $8 \%$ to $14 \%, 11.7 \%$ to $18.1 \%, 16.2 \%$ to $20.5 \%$, and $10.9 \%$ to $16.7 \%$, respectively, greater than those with treatment W1. For the same irrigation treatment, the values of TSS, $\mathrm{OA}$, and SSC in the three partitions were similar, but there were significant differences in VC and SAR among the partitions $(P<0.01)$. The VC and SAR values with $\mathrm{T} 1$ were $6 \%$ to $17.7 \%$ and $17 \%$ to $24.3 \%$, respectively, greater than those with T2 and T3. Overall, the ventilation treatments were ordered as $\mathrm{T} 1>\mathrm{T} 2>\mathrm{T} 3$ for $\mathrm{VC}$ and as $\mathrm{T} 1>\mathrm{T} 3>\mathrm{T} 2$ for SAR. These results indicate that both ventilation and irrigation treatments affected the tomato quality indexes. An analysis of all the yield and quality results showed that the yield and quality of greenhouse tomatoes with T2W2 were relatively optimal; therefore, we recommend T2W2 as the optimal combination of irrigation and greenhouse ventilation.

\section{Discussion}

\section{Effects of ventilation on surface evaporation and wind speed}

Surface evaporation in the greenhouse was influenced by solar radiation and ventilation. 
A

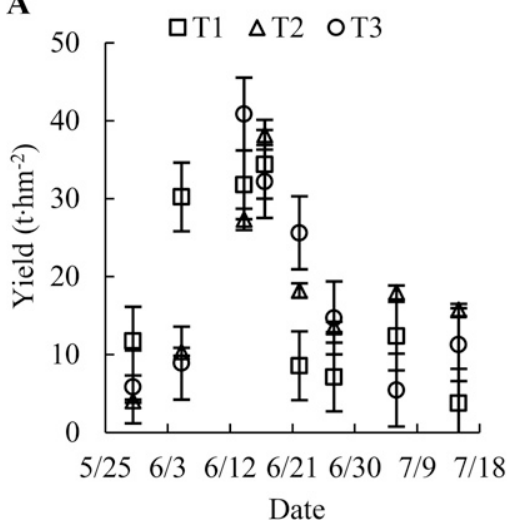

B

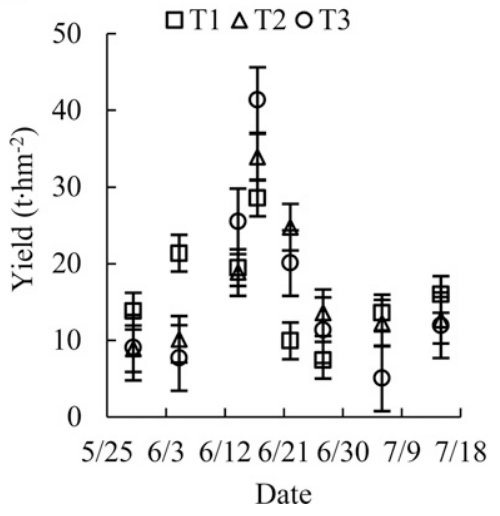

C

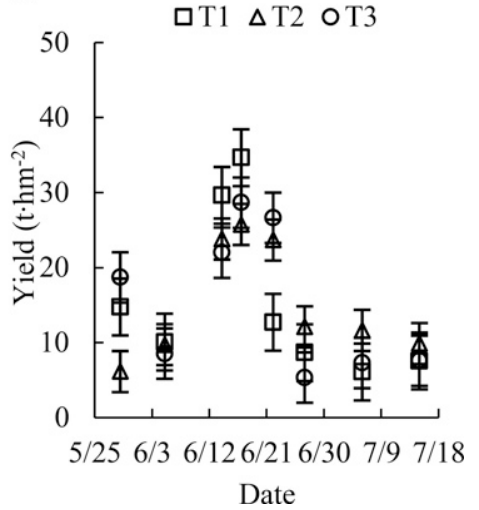

Fig. 7. Harvest and harvest date distribution of greenhouse tomato with W1 (A), W2 (B), and W3 (C).

A

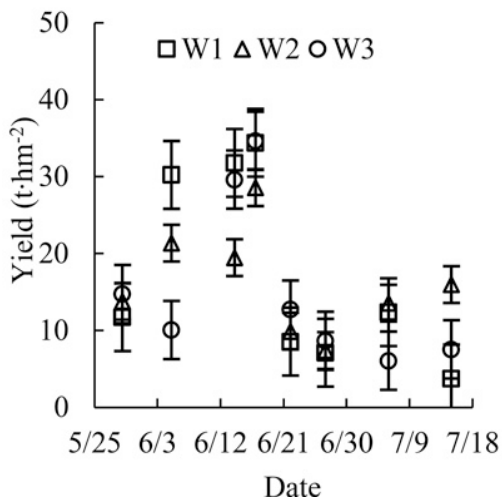

B

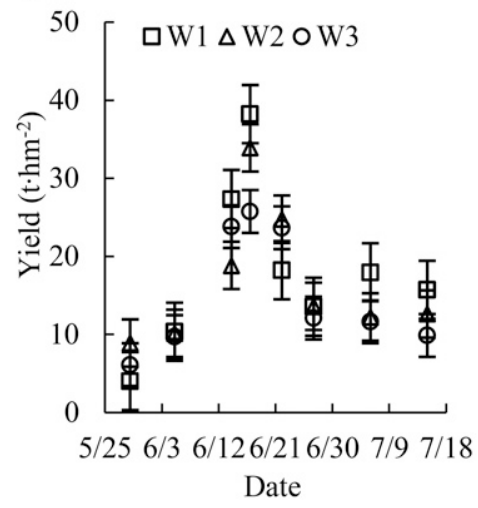

C

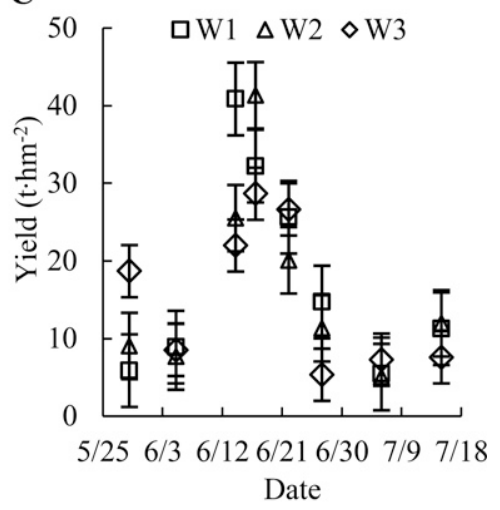

Fig. 8. Yield and harvest date distribution of greenhouse tomato with T1 (A), T2 (B), and T3 (C).

We found that variation in greenhouse $E_{p}$ for different ventilation modes matched the variation in $R_{a}$. There were no significant differences in $E_{p}$ for different treatments $(P>0.05)$ over the entire growth period. Thus $R_{a}$ was the factor that had the greatest effect on $E_{p}(\mathrm{Li}$, 2017; Su and Fan, 2020; Zhang et al., 2019b). $E_{p}$ reached a maximum value for the entire growth period with treatment $\mathrm{T} 2$, and that value of $E_{p}$ was much greater than the $E_{p}$ values with the other two ventilation treatments in windy weather. Using a daily time scale, with good ventilation, external wind pressure

Table 1. Comprehensive experimental scheme under different ventilation and water conditions.

\begin{tabular}{ccc}
\hline & \multicolumn{3}{c}{ Factors } \\
\cline { 2 - 4 } No. & Ventilation mode & Water treatment \\
\hline 1 & T1 & W1 $\left(0.9 E_{p}\right)$ \\
2 & T1 & W2 $\left(0.7 E_{p}\right)$ \\
3 & T1 & W3 $\left(0.5 E_{p}\right)$ \\
4 & T2 & W1 $\left(0.9 E_{p}\right)$ \\
5 & T2 & W2 $\left(0.7 E_{p}\right)$ \\
6 & T2 & W3 $\left(0.5 E_{p}\right)$ \\
7 & T3 & W1 $\left(0.9 E_{p}\right)$ \\
8 & T3 & W2 $\left(0.7 E_{p}\right)$ \\
9 & T3 & W3 $\left(0.5 E_{p}\right)$ \\
\hline
\end{tabular}

T1 had open vents on the north wall and roof of the greenhouse. T2 had open vents on the north and south walls and the roof. T3 had open vents on the north and south walls. $E_{p}$ is the cumulative evaporation of the $20-\mathrm{cm}$ standard evaporation pan. caused significant differences in surface evaporation in the greenhouse with different ventilation treatments $(P<0.05)$. This result indicated that ventilation was an important influence on $E_{p}$ (He et al., 2017). This result was similar to that found by Li et al. (2020), and similar conclusions have been found during studies of greenhouse cucumbers (Gong et al., 2015; Zou et al., 2005) and cantaloupes (Wang et al., 2011).

Variations in indoor wind speed were similar for all three ventilation treatments across the entire growth period, but there were differences during different growth stages. During the flowering and fruiting stage, $u$ was similar with $\mathrm{T} 1$ and $\mathrm{T} 3$, but there was a significant difference between these two treatments and T2 $(P<0.01)$. During

Table 2. Total soluble solid (TSS), vitamin $\mathrm{C}\left(\mathrm{V}_{\mathrm{c}}\right)$, organic acid (OA), and soluble sugar content (SSC) of drip-irrigated greenhouse tomato under different ventilation and water conditions.

\begin{tabular}{cccccc}
\hline Treatment & \multicolumn{1}{c}{ TSS $(\%)$} & \multicolumn{1}{c}{$\mathrm{V}_{\mathrm{c}}\left(\mathrm{mg} \cdot \mathrm{kg}^{-1}\right)$} & \multicolumn{1}{c}{ OA $(\%)$} & \multicolumn{1}{c}{ SSC $(\%)$} & \multicolumn{1}{c}{ SAR } \\
\hline T1W1 & $4.49 \pm 0.01 \mathrm{~g}$ & $157.11 \pm 3.53 \mathrm{cde}$ & $0.36 \pm 0.03 \mathrm{e}$ & $2.67 \pm 0.09 \mathrm{~b}$ & $7.58 \pm 0.84 \mathrm{a}$ \\
T1W2 & $4.81 \pm 0.01 \mathrm{e}$ & $180.33 \pm 11.07 \mathrm{ab}$ & $0.38 \pm 0.03 \mathrm{cde}$ & $2.78 \pm 0.06 \mathrm{ab}$ & $7.43 \pm 0.52 \mathrm{ab}$ \\
T1W3 & $5.12 \pm 0.01 \mathrm{a}$ & $185.48 \pm 5.05 \mathrm{a}$ & $0.42 \pm 0.02 \mathrm{abc}$ & $2.96 \pm 0.14 \mathrm{a}$ & $7.04 \pm 0.65 \mathrm{abc}$ \\
T2W1 & $4.48 \pm 0.02 \mathrm{~h}$ & $149.95 \pm 5.81 \mathrm{e}$ & $0.37 \pm 0.01 \mathrm{de}$ & $2.33 \pm 0.14 \mathrm{~d}$ & $6.31 \pm 0.20 \mathrm{~cd}$ \\
T2W2 & $4.79 \pm 0.01 \mathrm{f}$ & $153.25 \pm 8.74 \mathrm{de}$ & $0.40 \pm 0.02 \mathrm{bcde}$ & $2.59 \pm 0.10 \mathrm{bc}$ & $6.52 \pm 0.59 \mathrm{abcd}$ \\
T2W3 & $4.84 \pm 0.01 \mathrm{~d}$ & $167.54 \pm 5.59 \mathrm{bc}$ & $0.43 \pm 0.00 \mathrm{ab}$ & $2.72 \pm 0.03 \mathrm{~b}$ & $6.34 \pm 0.12 \mathrm{bcd}$ \\
T3W1 & $4.47 \pm 0.01 \mathrm{~h}$ & $148.11 \pm 5.45 \mathrm{e}$ & $0.39 \pm 0.01 \mathrm{bcde}$ & $2.40 \pm 0.07 \mathrm{~cd}$ & $6.10 \pm 0.28 \mathrm{~cd}$ \\
T3W2 & $4.88 \pm 0.01 \mathrm{c}$ & $164.56 \pm 6.80 \mathrm{~cd}$ & $0.42 \pm 0.01 \mathrm{bcd}$ & $2.64 \pm 0.07 \mathrm{~b}$ & $6.35 \pm 0.15 \mathrm{bcd}$ \\
T3W3 & $4.97 \pm 0.02 \mathrm{~b}$ & $169.35 \pm 6.97 \mathrm{bc}$ & $0.47 \pm 0.05 \mathrm{a}$ & $2.80 \pm 0.16 \mathrm{ab}$ & $5.94 \pm 0.52 \mathrm{~d}$ \\
\hline
\end{tabular}

Different letters in the same column indicate significant differences at $P=0.05$. 
found that variations in $T_{i}$ and $R H_{i}$ over the entire growth period were similar with all three ventilation treatments; however, there were differences with different growth stages and different weather conditions. During the flowering and fruiting stage, there were significant differences in $T_{i}$ among all three ventilation modes. During the later part of the harvest period, there were no significant differences in temperature among the three partitions because of a gradual increase in external air temperature and a decrease in cooling by ventilation. The effect of ventilation on reducing humidity was also greatly influenced by weather conditions. $R H_{i}$ differed significantly among partitions for different ventilation modes when there was a period of continuous sunshine $(P<0.01)$; however, on cloudy or rainy days, there were no significant differences among partitions, and humidity was close to the saturation point.

We also found that ventilation mode greatly affected the vertical distributions of humidity and temperature in the greenhouse. $T_{i}$ at $2 \mathrm{~m}$ was generally greater than $T_{i}$ at canopy height, but $R H_{i}$ was generally greater at canopy height than $R H_{i}$ at $2 \mathrm{~m}$. The difference between $T_{i}$ at $2 \mathrm{~m}$ and $T_{i}$ at canopy height with treatment $\mathrm{T} 2$ was significant $(P$ $<0.05)$, and the difference in relative humidity was more significant $(P<0.01)$. There were no significant differences in the vertical distributions of temperature or relative humidity across the entire growth period with treatments $\mathrm{T} 1$ and $\mathrm{T} 3$.

Irrigation had some effect on $T_{i}$ and $R H_{i}$ over the entire growth period. This was observed primarily for the behavior of $R H_{i}$ during different growth stages. However, the effect of irrigation was not as great as the effect of ventilation. This result was similar to the results obtained by Meng et al. (2016). We found that both ventilation and irrigation affected crop growth, and that regulating the combination of ventilation and irrigation can increase the beneficial effects of the greenhouse microenvironment on crop growth.

\section{Combined effects of ventilation and irrigation on crop yield and fruit quality}

Both ventilation mode and irrigation treatment had significant effects on crop yield and tomato fruit quality. This finding is consistent with the results of Yuan et al. (2003) and Zheng et al. (2011). There was a positive correlation between fruit yield and irrigation amount with each ventilation mode. This was because both the plant canopy and the maturing fruit require a large quantity of water during the middle and late growth stages; a high soil water content will satisfy the water requirements in the root zone and support movement of water through the plant and the accumulation of water and nutrients in the fruit, thus promoting fruit ripening and obtaining higher yield (Harel et al., 2014). Ventilation mode mainly affected environmental factors inside the greenhouse. Wind speed was greatest with treatment T2. This increased the rates of indoor and outdoor air exchange and reduced air temperature more rapidly than with treatments $\mathrm{T} 1$ and $\mathrm{T} 3$. The reduced air temperature, in turn, reduced the accumulated degree days, which are necessary for fruit ripening, thereby reducing the quantity of early ripening fruit available for picking during the initial period of the harvest stage.

A comparison of fruit quality indexes showed that ventilation primarily affected VC and SAR. Values of VC and SAR with T1 were significantly greater than those with $\mathrm{T} 2$ and $\mathrm{T} 3$ because the higher temperature in partition $\mathrm{T} 1$ increased the rate of synthesis of enzymes in fruit (Hooshmand et al., 2019; Liu et al., 2019a). Irrigation had a significant effect on TSS, VC, OA, and SSC; the values of all four indexes decreased as irrigation quantity increased. In contrast, yield increased as irrigation quantity increased. These results indicated that irrigation increases fruit yield and affects fruit quality, which is consistent with the findings of Li et al. (2012), who studied greenhouse melons. However, we observe that water deficit was proportional to fruit quality only within a certain range. When the soil water content in the root zone decreased below a certain level, the ability of the plant to synthesize carbohydrates was reduced, thus reducing fruit quality and decreasing crop yield.

\section{Conclusion}

We investigated the effects of different ventilation and irrigation treatments on the greenhouse microclimate, crop yield, and fruit quality of tomatoes. On a daily scale, ventilation had a significant effect on $E_{p}(P<$ $0.05)$. The maximum value of $E_{p}$ over the entire growth period occurred with treatment T2. Evaporation with T2 was much greater than that with $\mathrm{T} 1$ or $\mathrm{T} 3$ in windy weather. Ventilation had a significant effect on indoor wind speed, but there were differences at different growth stages. During the flowering and fruiting stage, there was no significant difference between $\mathrm{T} 1$ and $\mathrm{T} 3(P>0.05)$, but there was a significant difference between T2 and both T1 and T3 $(P<0.01)$. During the harvest stage, there were significant differences in wind speed among the three ventilation treatments $(P<0.01)$. Ventilation had a greater effect on the spatial distribution of both greenhouse humidity and temperature than irrigation. Air temperature and humidity over the entire growing period were ordered as $\mathrm{T} 3>\mathrm{T} 1>\mathrm{T} 2$. There were significant differences in $T_{i}$ among treatments during the flowering and fruiting stage $(P<0.05)$ but not during the harvest stage $(P>0.05)$. During periods of successive sunny days, there were significant differences in $R H_{i}$ among treatments $(P<0.01)$, but this was not the case for cloudy and rainy days $(P>0.05) . T_{i}$ at $2 \mathrm{~m}$ was greater than that at canopy height, whereas $R H_{i}$ at $2 \mathrm{~m}$ was less than that at canopy height. Ventilation and moisture combined had a great effect on crop yield and fruit quality. Irrigation amount was significantly positively correlated with yield $(P<$ 0.05 ) and significantly negatively correlated with the fruit quality indexes TSS, VC, OA, and $\operatorname{SSC}(P<0.05)$. Ventilation primarily affected the temporal distribution of fruit picked (i.e., tomato ripening) but had no significant effect on total yield $(P>0.05)$; the effect of ventilation on the indexes $\mathrm{VC}$ and SAR was significant $(P<0.01)$. In terms of optimizing both crop yield and fruit quality, we recommend T2W2 as the optimal combination of ventilation and drip irrigation for greenhouse tomatoes.

\section{Literature Cited}

Benni, S., P. Tassinari, F. Bonora, A. Barbaresi, and D. Torreggiani. 2016. Efficacy of greenhouse natural ventilation: Environmental monitoring and CFD simulations of a study case. Energy Build. 125:276-286, doi: 10.1016/j. enbuild.2016.05.014.

Choi, J.H., G.C. Chung, and S.R. Su. 1997. Effect of night humidity on the vegetative growth and the mineral composition of tomato and strawberry plants. Scientia Hort. 70(4):293-299, doi: 10.1016/S0304-4238(97)00055-1.

Chu, C.R., T.W. Lan, R.K. Tasi, T.R. Wu, and C.K. Yang. 2017. Wind-driven natural ventilation of greenhouses with vegetation. Biosyst. Eng. 164:221-234, doi: 10.1016/j.biosystemseng.2017. 10.008 .

Gong, X.W., J.S. Sun, H. Liu, H. Zhang, X.L. Wu and Y.H. Sun. 2015. Irrigation scheduling with a $20 \mathrm{~cm}$ standard pan for drip-irrigated cucumber growth in solar greenhouse in the North China Plain. Chinese J. Appl. Ecol. 26(11):3381-3388, doi: 10.13287/j.1001-9332.20150812.003.

Gong, X.W., J.K. Ge, Y.B. Li, S.S. Wang, H. Zhang, L. Zhang, Y.F. Liu, and H. Liu. 2020. Evaluation of the dual source model to simulate transpiration and evaporation of tomato plants cultivated in a solar greenhouse. Eur. J. Hort. Sci. 85(5):362-371.

Harel, D., H. Fadida, A. Slepoy, S. Gantz, and K. Shilo. 2014. The effect of mean daily temperature and relative humidity on pollen, fruit set and yield of tomato grown in commercial protected cultivation. Agronomy 4(1):167-177, doi: 10.3390/agronomy4010167.

Huang, Y.H., Y.L. Li, and X.Z. Wen. 2011. The effect of relative humidity on pollen vigor and fruit setting rate of greenhouse tomato under high temperature condition. Acta Agriculturae Boreali-occidentalis Sinica 20(11):105-110 (in Chinese).

He, K.S., D.Y. Chen, L.J. Sun, and Z.L. Liu. 2017. Effects of different wind conditions and window configuration on microclimate of single building plastic greenhouse in summer. Trans. Chinese Soc. Agr. Machinery 48(12):311$318+339$.

Hooshmand, M., M. Albaji, S.B. Nasab, and N.A.Z. Ansari. 2019. The effect of deficit irrigation on yield and yield components of greenhouse tomato (Solanum lycopersicum) in hydroponic culture in Ahvaz region, Iran. Scientia Hort. 254:84-90, doi: 10.1016/j.scienta. 2019.04.084

Kong, Y., S. Wang, J. Cheng, Z. Meng, and Q. Chen. 2009. Effects of different air velocity on container seedling traits of Muskmelon in greenhouse. Chinese Agronomic Bul. 25(1):137-140.

Li, X., G. Wang, X. Xue, Y. Xie and F. Chen. 2008. Effects of different wind speeds in greenhouse on growth and transpiration of potted sweet pepper. Acta Agr. Eng. (S2):214-218.

Li, J.M., X.G. Fan, F.F. Yan, H. Li, and D.S. Cai. 2017. Effect of irrigation amount based on transpiration model decision on melon yield 
and quality. J. Agr. Eng. 33(21):156-162, doi: 10.11975/j.issn.1002-6819.2017.21.018.

Li, N. 2017. Wind tunnel experimental study on influencing factors of water evaporation. J. Journal of Solar Energy 38(08):2258-2263.

Li, X.H., G.H. Gu, S.L. Yu, and L.S. Duan. 2020. Analysis on the trend of water surface evaporation and its influencing factors in Yunnan Province. Yangtze River 51(S2):63-67, doi: 10.16232/j.cnki.1001-4179.2020.S2.015.

Li, Y.J., B.Z. Yuan, B.Z. Long, and Y.H. Kang. 2012. Effects of different soil moisture limits on yield and quality of muskmelon under drip irrigation in greenhouse. J. Agr. Eng. 28(06):132-138, doi: 10.3969/j. issn. 1002-6819.2012.06.022.

Liu, B., Y. Cui, Y. Shi, X. Cai, Y. Luo, and L. Zhang. 2019b. Comparison of evapotranspiration measurements between eddy covariance and lysimeters in paddy fields under alternate wetting and drying irrigation. Paddy Water Environ. 17(4):725-739, doi: 10.1007/s10333019-00753-y.

Liu, H., J. Sun, A. Duan, Z. Liu and Y. Lian. 2010. Experiments on variation of tomato sap flow under drip irrigation conditions in greenhouse. Acta Agr. Eng. 26(10):77-82, doi: 10.3969/j. issn.1002-6819.2010.10.012.

Liu, H., H.H. Li, H.F. Ning, X.X. Zhang, S. Li, J. Peng, G.S. Wang, and J.S. Sun. 2019a. Optimizing irrigation frequency and amount to balance yield, fruit quality and water use efficiency of greenhouse tomato. Agr. Water Mgt. 226:105787, doi: 10.1016/j.agwat.2019.105787.

Liu, N.H., X.P. Jiang, J.F. Cheng, H. Li, and Z. Xiong. 2018. Current situation of foreign organic greenhouse horticulture and its inspiration for sustainable development of Chinese protected agriculture. Trans. Chinese Soc. Agr. Eng. (Transactions of the CSAE) 34(15):1-9 (in Chinese), doi: 10.11975/j.issn.1002-6819.2018.15.001.

Meng, L.L., J.L. Liu, J. Liu, L.R. Xia, Y.B. Tang, and L.J. Yu. 2016. Study on temperature and humidity of plastic greenhouse under different ventilation modes in the Yangtze-Huai region in hot season. Agr. Sci. Technol. 17(12):2885-2888, doi: 10.16175/j.cnki.1009-4229.2016.12.048.

Orgaz, F., M.D. Fernández, S. Bonachela, M. Gallardo, and E. Fereres. 2005. Evapotranspiration of horticultural crops in an unheated plastic greenhouse. Agr. Water Mgt. 72(3):81-96, doi: 10.1016/j.agwat.2004.09.010.

Peng, Z.G., B.Z. Zhang, Y. Liu, L. Wang, L.J. Du, and B. Lei. 2018. Total water consumption control based on irrigation system optimization and planting structure adjustment. J. Agr. Eng. 34(3):103-109, doi: 10.11975/j.issn.1002-6819. 2018.03.014.

Shamshiri, R.R., J.W. Jones, K.R. Thorp, A. Desa, M.H. Che, and T. Sima. 2018. Review of optimum temperature, humidity, and vapour pressure deficit for microclimate evaluation and control in greenhouse cultivation of tomato: A review. Intl. Agrophys. 32(2):287-302, doi: 10.1515/intag-2017-0005.

$\mathrm{Su}, \mathrm{W} .2016$. CFD simulation study on the effects of natural ventilation on microclimate in solar greenhouse. Nanjing University of Information Science \& Technology.

Su, Y.Y. and X.K. Fan. 2020. Study and analysis of main meteorological factors affecting evapotranspiration based on weighing method. Agr. Res. Arid Areas 38(03):40-48, doi: 10.7606/j. issn. 1000-7601.2020.03.06.

Traore, S., L. Zhang, A. Guven, and G. Fipps. 2020. Rice yield response forecasting tool (YIELDCAST) for supporting climate change adaptation decision in Sahel. Agr. Water Mgt. 239:106242, doi: 10.1016/j.agwat.2020.106242.

Vanthoor, B.H.E., C. Stanghellini, H.E.J. Van, and H.B. Pieter. 2011. A methodology for modelbased greenhouse design: Part 1, a greenhouse climate model for a broad range of designs and climates. Biosyst. Eng. 110(4):363-377, doi: 10.1016/j.biosystemseng.2011.06.001.

Wang, D., Y. Li, T. Zhang, L. Zhou, J. Ge, L. Zhang, M. Dyck, and H. Feng. 2020. Greenhouse gas emissions and carbon footprint under gravel mulching on China's Loess Plateau. Agron. J. 112(2):733-747, doi: 10.1002/agj2.20022.

Wang, L. and Z.J. Zhou. 2017. Determination of calculated method for necessary ventilation rate and its determination analysis of parameter value. Trans. Chinese Soc. Agr. Eng. (Transactions of the CSAE) 33(5):190-198 (in Chinese), doi: 10.11975/j.issn.1002-6819.2017.05.028.

Wang, J.J., J.M. Li, Y.L. Zhang, Z.M. Zhao, and Z.R. Zou. 2011. Effects of greenhouse temperature and humidity and irrigation amount on the growth and development of muskmelon. Northern Hort. (06):50-55.

Xie, H.X. and H.J. Cai. 2013. Quality and yield characteristics of greenhouse Melon under drip irrigation under mulch. J. Irr. Drainage 32(4):138-140, doi: 10.7631/j.issn.1672-3317. 2013.04.035.

Yuan, H.B., L. Li, and J.H. Wang. 2015. Control method for greenhouse climate based on temperature integration. Trans. Chinese Soc. Agr. Eng. 31(11):221-227 (in Chinese), doi: 10.11975/j.issn.1002-6819.2015.11.032.

Yang, Z.C., Z.R. Zou, J. Wang, S. Chen and J. Li. 2007. Effects of airflow velocity in greenhouse on the growth and development of muskmelon. Acta Agr. Eng. 23(3):198-201.

Yan, L.L., H.W. Jing, E.C. Bao, Y.F. Cao, T.H Pan, T.T. Shen, H.T. Wang, and Z.R. Zou. 2020. Effects of different natural ventilation modes on solar greenhouse performance. J. China Agr. Univ. 25(03):71-78, doi: 0.11841/j. issn.1007-4333.2020.03.09.

Yuan, B.Z., J. Sun, and S. Nishiyama. 2003. Effect of drip irrigation on strawberry growth and yield inside a plastic greenhouse. Biosyst. Eng. 87(2):237-245, doi: 10.1016/j.biosystemseng. 2003.10.014

Zhang, L., S. Traore, J. Ge, Y. Li, S. Wang, G. Zhu, Y. Cui, and G. Fipps. 2019a. Using boosted tree regression and artificial neural networks to forecast upland rice yield under climate change in Sahel. Comput. Electron. Agr. 166:105031, doi: 10.1016/j.compag.2019.105031.

Zhang, L., S. Traore, Y. Cui, Y. Luo, G. Zhu, B. Liu, G. Fipps, R. Karthikeyan, and V. Singh. 2019b. Assessment of spatiotemporal variability of reference evapotranspiration and controlling climate factors over decades in China using geospatial techniques. Agr. Water Mgt. 213:499-511, doi: 10.1016/j.agwat.2018.09.037.

Zou, Z.R., Q.M. Li, and Z.Q. He. 2005. Effects of different irrigation maximums on growth dynamics, yield and quality of cucumber during fruit-bearing stage in greenhouse. Trans. Chinese Soc. Agr. Eng. (Transactions of the CSAE) 21(Supp):77-81.

Zheng, G.B., D.J. Kong, Y.P. Zhang, S.H. Guo, and J.X. Zhu. 2011. Effects of different irrigation amount on yield, quality and water use efficiency of tomato in solar greenhouse. Northern Hort. Sci. (11):47-49. 